\title{
Hepatitis A outbreak among men who have sex with men (MSM) predominantly linked with the EuroPride, the Netherlands, July 2016 to February 2017
}

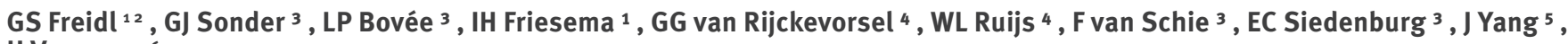
H Vennema 6

1. Centre for Infectious Diseases, Epidemiology and Surveillance, Centre for Infectious Disease Control, National Institute for Public Health and the Environment (RIVM), Bilthoven, the Netherlands

2. European Programme for Intervention Epidemiology Training (EPIET), European Centre for Disease Prevention and Control (ECDC), Stockholm, Sweden

3. Department of Infectious Disease Control, Public Health Service Amsterdam (GGD), Amsterdam, the Netherlands

4. National Coordination Centre for Communicable Disease Control, Centre for Infectious Disease Control, National Institute for Public Health and the Environment (RIVM), Bilthoven, the Netherlands

5. Centers for Infectious Disease Control, Taipei, Taiwan

6. Centre for Infectious Diseases Research, Diagnostics and Screening, Centre for Infectious Disease Control, National Institute for Public Health and the Environment (RIVM), Bilthoven, the Netherlands

Correspondence: Gudrun S Freidl (gudrun.freidl@rivm.nl)

Citation style for this article:

Freidl GS, Sonder GJ, Bovée LP, Friesema IH, van Rijckevorsel GG, Ruijs WL, van Schie F, Siedenburg EC, Yang J, Vennema H. Hepatitis A outbreak among men who have sex with men (MSM) predominantly linked with the EuroPride, the Netherlands, July 2016 to February 2017. Euro Surveill. 2017;22(8):pii=30468. DOI: http:// dx.doi.org/10.2807/1560-7917.ES.2017.22.8.30468

Article submitted on 09 February 2017 / accepted on 22 February 2017 / published on 23 February 2017

Between July 2016 and February 2017, 48 male cases of hepatitis A were notified in the Netherlands. Of these, 17 identified as men who have sex with men (MSM). Ten of the 13 cases for whom sequencing information was available, were infected with a strain linked with the EuroPride that took place in Amsterdam in 2016. This strain is identical to a strain that has been causing a large outbreak among MSM in Taiwan.

In December 2016, the European Centre for Disease Prevention and Control (ECDC) issued a Rapid Risk Assessment reporting of two distinct hepatitis $A$ virus (HAV) genotype IA strains circulating among men who have sex with men (MSM) in the United Kingdom (UK) and the Netherlands in 2016. Germany, Italy and Spain had also reported a recent increase in male HAV cases [1].

The outbreak is ongoing with 37 cases reported in the UK between July 2016 and January 2017 [2] and 30 cases in Berlin between mid-November 2016 and end of January 2017 [3]. Here we describe the current situation in the Netherlands including potential links to this international hepatitis A outbreak.

\section{Case definition}

A case was defined as a person who (i) met the surveillance definition of a case of hepatitis $A$, (ii) selfidentified as MSM or had MSM contact i.e. sexual contact with another man two months before the onset of symptoms, (iii) developed symptoms after mid-2016 (3 July 2016) and (iv) was a resident in the Netherlands.
The surveillance case definition comprises (i) non-specific symptoms (e.g. fatigue, abdominal pain, loss of appetite, intermittent nausea and vomiting), (ii) fever or jaundice and (iii) laboratory confirmation or an epidemiological link with a laboratory-confirmed case i.e. either hepatitis A-specific IgM antibodies in serum or detection of HAV in serum or stool by means of PCR [4].

\section{Surveillance of hepatitis $\mathrm{A}$ in the Netherlands}

In the Netherlands, hepatitis A is a notifiable disease. Laboratories and physicians report HAV infections within one working day to the regional Public Health Services (PHS). The PHS then collect epidemiological information on demographics, occupation, symptoms, suspected source / country of infection, MSM contact (for males only) and consumption of specific food items. The PHS reports all information in the national surveillance system for notifiable diseases. In addition, serum and / or stool samples of HAV cases are routinely sent to the National Institute of Public Health and the Environment (RIVM) for molecular analysis. In case men did not explicitly report having had MSM contact two months before disease onset, MSM status was assessed by asking whether they identified themselves as MSM.

\section{Molecular analyses}

HAV IgM-positive serum samples were analysed by sequence analysis of a $460 \mathrm{nt} P C R$ fragment in the VP1/ $\mathrm{P}_{2} \mathrm{~A}$ region according to a shared protocol available through Hepatitis A Lab-Network HAVNET [5]. 
Epidemic curve of hepatitis A cases by MSM status and week of onset of illness, July 2016-February 2017, the Netherlands $(\mathrm{n}=19)$

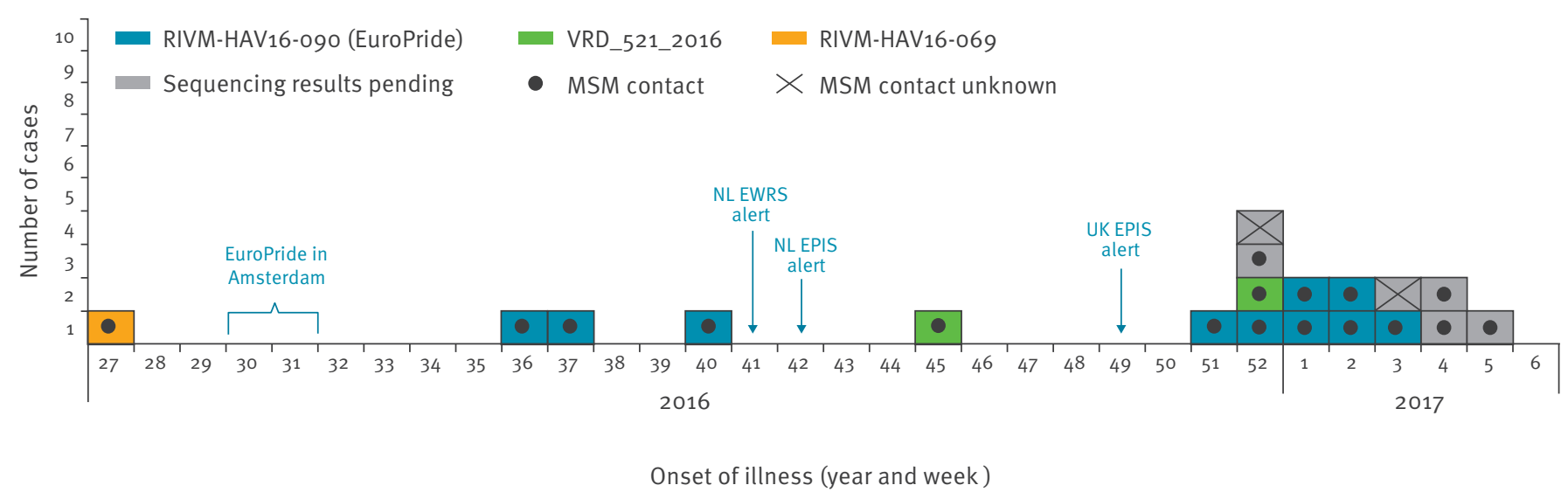

EPIS: Epidemic Intelligence Information System; EWRS: Early Warning and Response System; MSM: men who have sex with men; NL: the Netherlands; UK: United Kingdom.

Two cases for whom MSM status was unknown at the time of the investigation, are also included.

\section{Outbreak description}

In the first half of 2016 (including week 26), 22 sporadic hepatitis $A$ cases were notified through the Dutch national surveillance system. Half of these were men and none reported MSM contact.

On 19 September 2016 (week 38), the outbreak investigation was triggered by the notification of two male cases of hepatitis A, in their 305 and 40s, who fell ill in mid-September. Both cases reported having had MSM contact during the EuroPride. The EuroPride, which took place in Amsterdam between 29 July and 6 August, is an international event to celebrate equality rights of the lesbian, gay, bisexual and transgender community. In 2016, this event attracted over half a million visitors [6]. Sequencing showed that strains from both cases were identical (RIVM-HAV16-090). Given the international character of the EuroPride, alerts were placed on the Early Warning and Response System (EWRS) and on ECDC's Epidemic Intelligence Information System for Food- and Waterborne diseases (EPIS-FWD) to inform other European countries.

From mid-2016 (week 27) to 7 February 2017, 48 male cases of hepatitis A were reported nationally. Of these, 17 identified as MSM. Two cases did not (yet) meet the case definition, as MSM status was unknown at the time of the investigation. For comparison, in 2013, 2014 and 2015, 56, 58 and 45 male cases of hepatitis A were reported each year, respectively. Among these, none were identified as MSM.

The Table shows the characteristics of the cases recorded in the current outbreak. The onset of illness ranged from week 27, 2016 to week 5, 2017 (Figure 1).
Of the 17 cases, 11 were born outside the Netherlands (Argentina, Brazil, Canada, France, Italy, Lebanon, Peru, Spain $(n=3)$, Surinam). The median age of the 17 cases was 33 years (range: $26-52$ ). None of the cases were vaccinated and about a third was hospitalised (Table). Sequence information was available for 13 of the 17 cases, which showed co-circulation of three different hepatitis A strains (Table, Figure 2).

Ten of the 13 cases with available typing information were infected with the EuroPride strain. The majority of cases $(n=11)$, irrespective of sequence type, clustered in the Public Health Service region of Amsterdam, whereas other Public Health Service regions only reported incidental cases (Table, Figure 3).

In comparison, among the 29 male cases who became ill after mid-2016 and were not MSM (median age: 20.5 years, range: $0-82$ ) we found strains that were unrelated to the current outbreak. We detected genotype IA and IB strains from Morocco, IB strains from Egypt, Turkey, West Africa and East Africa, a IIA strain from Cameroon, a IIIA strain from Romania or no hepatitis A virus, respectively. As none of these cases was infected with a strain involved in the current outbreak, we are confident that these cases reported their MSM status truthfully.

\section{EuroPride strain RIVM-HAV16-090}

When comparing sequence information of the EuroPride strain with available sequences in the databases HAVNET [5] and GenBank, we found that the EuroPride strain was $99.57 \%$ identical to a sequence submitted by Japan (accession number: ABo20565, release date: 14 August 2001). In addition, in response to a post on ProMED-mail from May 2016 that reported 


\section{FIGURE 2}

Phylogenetic analysis of virus strains from hepatitis A cases who self-identified as men who have sex with men, the Netherlands, 2000-2017

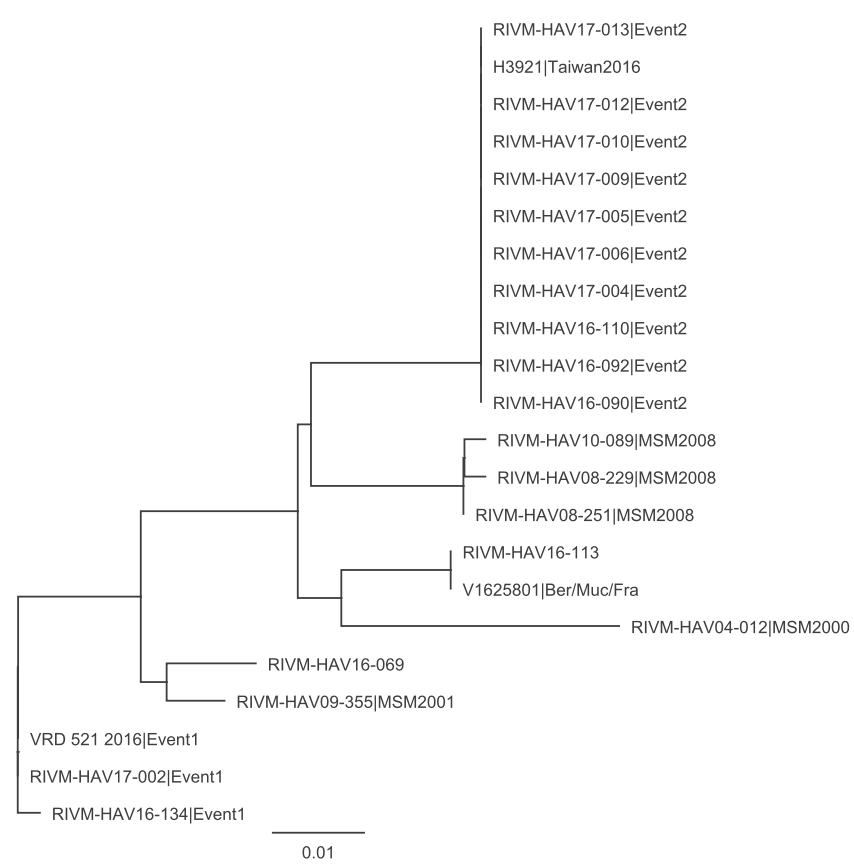

Neighbour-joining tree of sequences of $445 \mathrm{nt}$ of the VP1/P2A region of hepatitis $A$ virus strains.

The tree was constructed in PHYLIP (DNADIST) (Joe Felsenstein, Department of Genome Sciences, University of Washington, Seattle, USA). Strains are identified by sample number and cluster. Event 1 and Event 2 refer to terminology used in the Rapid Risk Assessment published by the European Centre for Disease Prevention and Control (ECDC) [1]. Event 1 refers to strains detected in the United Kingdom and Spain [2]. Event 2 refers to the EuroPride strain detected in the Netherlands and the strain circulating in Taiwan in 2016, respectively. One asymptomatic case is identical to a sequence that caused a cluster in Germany (Ber/ Muc/Fra) [3]. For comparison, we also included older hepatitis A virus strains detected in men who have sex with men (MSM) in 2000, 2001 and 2008, respectively.

on a hepatitis A outbreak among MSM in Taiwan with 275 notified cases [7], we investigated whether the EuroPride strain might be related to the Taiwanese outbreak strain. Direct comparison and phylogenetic analyses showed that the Taiwanese outbreak strain was identical to the EuroPride strain (Figure 2). Eight of the ten cases reported to have likely been infected in the Netherlands, and a further two cases were likely infected in Barcelona, Spain $(n=2$; onset of illness for both cases: week 2, Figure 1).

\section{Strains VRD $521 \_2016$ and RIVM-HAV 16-069}

Two cases were infected with strain VRD_521_2016, first reported by the UK in December 2016 and likely imported from Spain several times $[1,2]$. One of the Dutch cases reported having travelled to Spain (onset of illness in week 45), whereas the other case stated to have likely been infected in the Netherlands (onset of illness week 52, Figure 1).

\section{FIGURE 3}

Geographic distribution of hepatitis A cases who selfidentified as men who have sex with men, by available sequence information, the Netherlands, July 2016February 2017 ( $\mathrm{n}=19)$

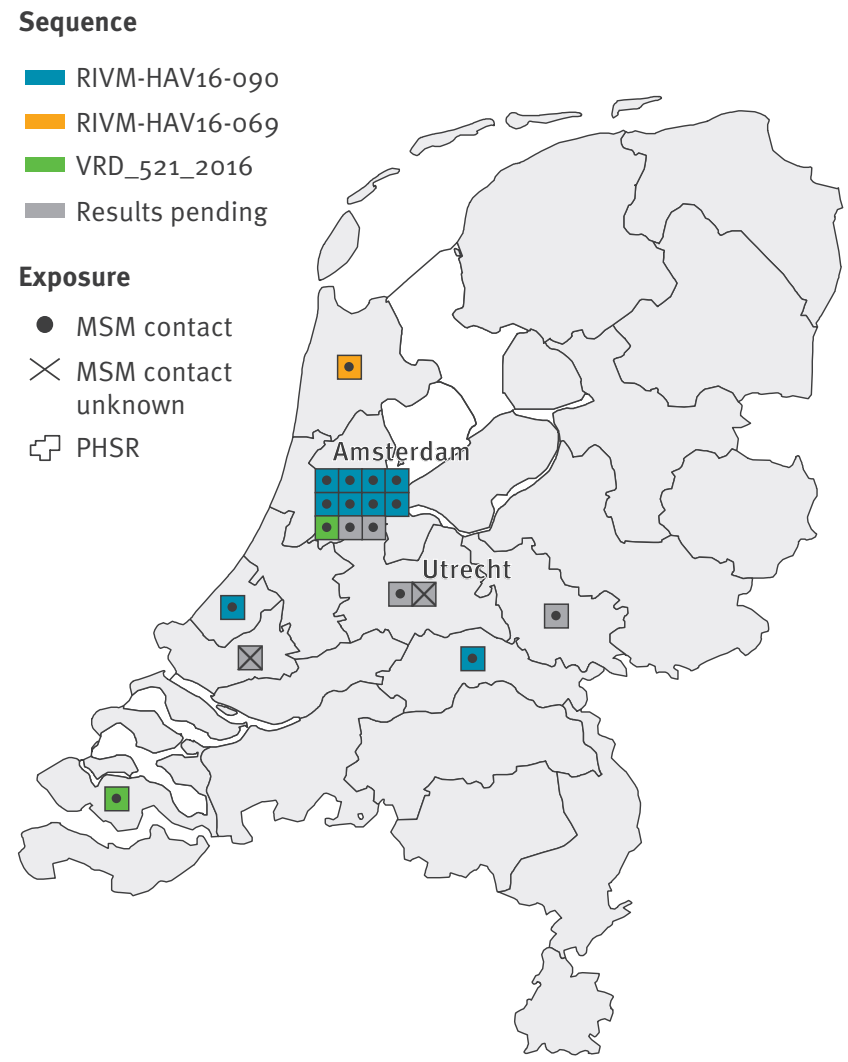

MSM: men who have sex with men; PHSR: Public Health Service region.

Two cases for whom MSM status was unknown at the time of the investigation, are also shown. Notified cases are centred in the respective Public Health Service region. The majority of cases $(n=11)$ occurred in the PHSR Amsterdam.

One case infected with strain RIVM-HAV16-069 reported having travelled to Argentina and became ill shortly before the EuroPride (week 27). The UK also reported one MSM case with the same sequence [2].

\section{Discussion}

Here we report on an ongoing hepatitis A outbreak among MSM in the Netherlands that started in 2016. Hepatitis $A$ is an acute, self-limiting liver disease which is transmitted via the faecal-oral route. Infection occurs via contaminated food or water, or through person-toperson contact, including sexual contact. The average incubation period is 28 days (range: $15-50$ days) [8]. In western Europe hepatitis A endemicity is low [9] and is primarily associated with travelling to endemic countries [10] or consumption of contaminated, imported food [11]. Outbreaks among MSM have also been described [12]. In Europe, the last outbreak of hepatitis A among MSM occurred between 2008 and 2011 [13]. 
Characteristics of hepatitis A cases by MSM status and strain, the Netherlands, July 2016-February 2017 (n = 19)

\begin{tabular}{|c|c|c|c|c|c|c|}
\hline \multirow[b]{2}{*}{$\begin{array}{l}\text { Hepatitis A } \\
\text { strain }\end{array}$} & \multicolumn{5}{|c|}{ Men who have sex with men (MSM) } & \multirow{2}{*}{$\begin{array}{l}\text { Sequence information } \\
\text { and MSM status } \\
\text { unknown / pending }\end{array}$} \\
\hline & $\begin{array}{l}\text { RIVMHAV } 16090 \\
\text { (EuroPride) }\end{array}$ & $\begin{array}{l}\text { VRD_521_2016 } \\
\text { (UK/Spain) }\end{array}$ & RIVM-HAV16-069 & $\begin{array}{l}\text { Sequence information } \\
\text { pending }\end{array}$ & Total & \\
\hline $\begin{array}{l}\text { Number of } \\
\text { cases }\end{array}$ & 10 & 2 & 1 & 4 & 17 & 2 \\
\hline $\begin{array}{l}\text { Number per } \\
\text { 10-year age } \\
\text { group }\end{array}$ & $\begin{array}{l}20-29(n=3) \\
30-39(n=4) \\
40-49(n=3) \\
\end{array}$ & $\begin{array}{l}20-29(n=1) \\
40-49(n=1)\end{array}$ & $20-29(n=1)$ & $\begin{array}{l}20-29(n=2) \\
30-39(n=1) \\
50-59(n=1)\end{array}$ & $\begin{array}{c}33(26-52) \\
\text { Median } \\
(\min -\max ) \\
\end{array}$ & $\begin{array}{l}20-29(n=1) \\
40-49(n=1)\end{array}$ \\
\hline $\begin{array}{l}\text { Number } \\
\text { of cases } \\
\text { hospitalised }\end{array}$ & 3 & 1 & 1 & 0 & 5 & 0 \\
\hline $\begin{array}{l}\text { Number } \\
\text { of cases } \\
\text { vaccinated } \\
\text { against } \\
\text { hepatitis A }\end{array}$ & 0 & 0 & 0 & 0 & 0 & 0 \\
\hline $\begin{array}{l}\text { Suspected } \\
\text { place of } \\
\text { infection }\end{array}$ & $\begin{array}{c}\text { The Netherlands } \\
(n=8) \\
\text { Spain, Barcelona } \\
(n=2)\end{array}$ & $\begin{array}{l}\text { The Netherlands } \\
\qquad(n=1) \\
\text { Spain }(n=1)\end{array}$ & Argentina $(n=1)$ & $\begin{array}{l}\text { The Netherlands }(n=3)^{\text {a }} \\
\text { Germany, Berlin }(n=1)\end{array}$ & 4 & The Netherlands $(n=1)^{b}$ \\
\hline
\end{tabular}

MSM: men who have sex with men; UK: United Kingdom.

a One case reported Portugal as second suspected country of infection.

${ }^{b}$ For one case information on suspected place of infection was not available.

Ages were estimated because only year of birth was known.

Characteristics of two male cases of hepatitis A for whom MSM status was unknown at the time of the investigation, are shown separately.

Between 2012 and mid-2016, hepatitis A infection in MSM was only notified twice in the Netherlands.

In the currently ongoing outbreak in the Netherlands, the majority of cases for whom sequence information was available, were infected with strain RIVMHAV16-090. This strain had only been detected once before in 2010 and was absent in the Netherlands until it was detected in two MSM cases who attended the EuroPride in 2016. The strain is identical with a strain causing an ongoing outbreak among MSM in Taiwan. As at 29 September 2016, Taiwan reported 845 hepatitis $A$ cases among MSM, of which $56 \%$ were HIV-positive or had another sexually transmitted diseases [14].

In the Netherlands, information on HIV status is not routinely collected for hepatitis $A$ surveillance purposes. In the course of this outbreak investigation, in week 43, we detected one HAV infection in a HIVpositive MSM who was asymptomatic and therefore did not meet the case definition. Sequencing showed infection with a strain identical to the Berlin/Munich/ Frankfurt HAV cluster in Germany (V16-25801) [3]. Asymptomatic individuals, even if they do not fulfil the case definition, can still be epidemiologically relevant and should therefore be included in epidemiological analyses.

In the Netherlands, besides risk groups, i.e. persons with chronic liver disease or occupational exposure to HAV, hepatitis A vaccination is recommended to individuals who travel to HAV endemic countries. Hepatitis A vaccine uptake is unknown. Because of several outbreaks among European and Dutch MSM $[15,16]$, hepatitis $A$ vaccination is also recommended to MSM in the Netherlands. For MSM, vaccination against $\mathrm{HAV}$ is available at reduced costs and is administered in combination with hepatitis $B$ vaccine that is free of charge for this risk group. The uptake of hepatitis $B$ vaccination among MSM in Amsterdam is high and hepatitis B incidence has dropped markedly since 2005 [17]. In contrast, financial aspects might hamper wide uptake of hepatitis A vaccination. Vaccination coverage among MSM is unknown.

In the Netherlands, hepatitis A control is based on vaccination of household- and other close contacts [4]. Tracing and vaccination of sexual contacts of MSM can be challenging due to anonymous sexual contacts. To better understand transmission chains and the epidemiology of this outbreak, we recently introduced an additional, more detailed questionnaire for hepatitis A-positive MSM to complement routinely collected epidemiological data. Given the high outbreak potential of hepatitis $A$ in the MSM community and the high interconnectedness through global travel of this risk group [18], increasing awareness of hepatitis A among MSM as well as health professionals at sexually transmitted disease clinics and public health services should be emphasised. To increase hepatitis A vaccination uptake, the Regional Public Health Services and 'STI AIDS the Netherlands' (centre of expertise for HIV and 
other sexually transmitted infections) have been engaging in activities to remind professionals and the Dutch MSM community of the availability of hepatitis A vaccination within the hepatitis $B$ vaccination programme.

\section{Acknowledgements}

We would like to thank staff from the Public Health Service regions (GGD) involved in the investigation and management of the outbreak. We would also like to thank Ben Bom from SSC Campus / RIVM for creating the map and Christopher Williams for critical review of the manuscript.

No external funding was required to carry out this work.

\section{Conflict of interest}

None declared.

\section{Authors' contributions}

GSF analysed epidemiological data and wrote the manuscript. LPMJB, FvS, ECS and GJBS interviewed cases and coordinated outbreak investigation within the Public Health Service region GGD Amsterdam. IHMF, WLMR, GGCvR were involved in the outbreak management and coordination of the outbreak response. J-YY provided sequence information from Taiwan. HV conducted molecular analyses. All authors commented on the manuscript.

\section{References}

1. European Centre for Disease Prevention and Control (ECDC). Hepatitis A outbreaks in the EU/EEA mostly affecting men who have sex with men. Stockholm: ECDC; 19 Dec 2016. Available from: http://ecdc.europa.eu/en/publications/Publications/1312-2016-RRA-Hepatitis\%20A-United\%20Kingdom.pdf

2. Beebeejaun K, Degala S, Balogun K, Simms I, Woodhall SC, Heinsbroek E, et al. Outbreak of hepatitis A associated with men who have sex with men (MSM), England, July 2016 to January 2017. Euro Surveill. 2017;22(5):30454. DOI: 10.2807/1560-7917.ES.2017.22.5.30454 PMID: 28183392

3. Werber D, Michaelis K, Hausner M, Sissolak D, Wenzel J, Bitzegeio J, et al. Ongoing outbreaks of hepatitis A among men who have sex with men (MSM), Berlin, November 2016 to January 2017 - linked to other German cities and European countries. Euro Surveill. 2017;22(5):30457. DOI: 10.2807/15607917.ES.2017.22.5.30457 PMID: 28183391

4. National Coordination Centre for Communicable Disease Control. (Landelijke Coordinatie Infectieziektenbestrijding ( $\mathrm{LCl}$. $\mathrm{LCl}$-richtlijn Hepatitis $\mathrm{A}$. [ $\mathrm{LCl}$ directive on hepatitis A]. Bilthoven: LCI. [Accessed: 5 Feb 2017]; Dutch. Available from: http://www.rivm.nl/Documenten_en_publicaties/ Professioneel Praktisch/Richtlijnen/Infectieziekten/ LCI_richtlijnen/LCI_richtlijn_Hepatitis_A

5. National Institute of Public Health and the Environment (RIVM). HAVNET Hepatitis A Lab Network. Bilthoven: RIVM; [Accessed 5 Feb 2017]. Available from: http://www.rivm.nl/en/Topics/H/ HAVNET

6. Nieuws RTL. Recorddrukte Canal Parade geëvenaard: 560.000 mensen op de been. [Record visitor numbers at Canal pride: 560.000 people present]. Hilversum: RTL Nieuws; 2016. Dutch. Available from: http://www.rtlnieuws.nl/nederland/ recorddrukte-canal-parade-geevenaard-560000-mensen-opde-been

7. ProMED-mail. Hepatitis A - Taiwan: Increased MSM incidence. Archive. 2016;4230111(: 20160518):18. Available from: http:// www.promedmail.org/post/20160518.4230111

8. World Health Organization (WHO). Hepatitis A vaccines.Wkly Epidemiol Rec. 2000;75(5):38-44.PMID: 10693358

9. World Health Organization (WHO). The Global Prevalence of Hepatitis A Virus Infection and Susceptibility: A Systematic Review. Geneva: WHO; Jun 2009. Available from: http://apps.
who.int/iris/bitstream/10665/70180/1/WHO_IVB_10.01_eng. pdf

10. Wu D, Guo CY. Epidemiology and prevention of hepatitis A in travelers.J Travel Med. 2013;20(6):394-9. DOI: 10.1111/ jtm.12058 PMID: 24165384

11. Gossner CM, Severi E. Three simultaneous, food-borne, multi-country outbreaks of hepatitis $A$ virus infection reported in EPIS-FWD in 2013: what does it mean for the European Union?Euro Surveill. 2014;19(43):20941. DOI: $10.2807 / 1560$ 7917.ES2014.19.43.20941 PMID: 25375903

12. Urbanus AT, van Houdt R, van de Laar TJ, Coutinho RA. Viral hepatitis among men who have sex with men, epidemiology and public health consequences. Euro Surveill. 2009;14(47):19421.PMID: 19941800

13. Bordi L, Rozera G, Scognamiglio P, Minosse C, Loffredo M, Antinori A, et al. . Monophyletic outbreak of Hepatitis A involving HIV-infected men who have sex with men, Rome, Italy 2008-2009.J Clin Virol. 2012;54(1):26-9. DOI: 10.1016/j. jcv.2012.01.009 PMID: 22341552

14. Centers for Disease Control (CDC) R.O.C. Taiwan. As Taiwan CDC to expand target groups for government-funded hepatitis $A$ vaccination beginning October 1,2016 , eligible individuals urged to get vaccinated at contracted healthcare facilities. Press release. Taipei: CDC R.O.C. Taiwan; 30 Sep 2016. Available from: http://www.cdc.gov.tw/english/info.aspx?treei $\mathrm{d}=\mathrm{bc2d} 4 \mathrm{e} 89 \mathrm{~b} 154059 \mathrm{~b} \&$ nowtreeid=ee0a2987cfba3222\&tid=55 7BA6C13262600C

15. van Steenbergen JE, Tjon G, van den Hoek A, Koek A, Coutinho RA, Bruisten SM. Two years' prospective collection of molecular and epidemiological data shows limited spread of hepatitis A virus outside risk groups in Amsterdam, 20002002.J Infect Dis. 2004;189(3):471-82. DOI: $10.1086 / 381152$ PMID: 14745705

16. Stene-Johansen K, Tjon G, Schreier E, Bremer V, Bruisten S, Ngui SL, et al. Molecular epidemiological studies show that hepatitis $A$ virus is endemic among active homosexual men in Europe. J Med Virol. 2007;79(4):356-65. DOI: 10.1002/ jmv.20781 PMID: 17311331

17. van Rijckevorsel G, Whelan J, Kretzschmar M, Siedenburg E, Sonder G, Geskus R, et al. Targeted vaccination programme successful in reducing acute hepatitis $B$ in men having sex with men in Amsterdam, the Netherlands. J Hepatol. 2013;59(6):1177-83. DOI: 10.1016/j.jhep.2013.08.002 PMID: 23954670

18. Lee VC, Sullivan PS, Baral SD. Global travel and HIV/STI epidemics among MSM: what does the future hold?Sex Health. 2017;14(1):51. DOI: 10.1071/SH16099 PMID: 28055822

\section{License and copyright}

This is an open-access article distributed under the terms of the Creative Commons Attribution (CC BY 4.0) Licence. You may share and adapt the material, but must give appropriate credit to the source, provide a link to the licence, and indicate if changes were made.

This article is copyright of the authors, 2017. 